\title{
Pharmacology of Sedation Agents and Reversal Agents
}

\author{
Argyro Fassoulaki Kassiani Theodoraki Aikaterini Melemeni \\ Department of Anesthesiology, Aretaieio Hospital, Medical School, University of Athens, Athens, Greece
}

\section{Key Words}

Benzodiazepines • Opioids · Pharmacokinetics

\begin{abstract}
Sedation for gastrointestinal endoscopies is obtained by opioids, benzodiazepines, propofol, ketamine and/or droperidol. The pharmacokinetic profile of some sedatives/anesthetics renders them advantageous over others. Opioids, mainly pethidine and fentanyl, are the most popular. Though newer opioids provide a faster recovery, fentanyl is safe and advantageous due to its lower cost. Remifentanil, due to its pharmacokinetic profile (elimination half-life: $9 \mathrm{~min}$ ), is advantageous for ambulatory patients, though it is not known whether the high cost compensates the benefits. Midazolam is the benzodiazepine of choice as it has a shorter duration of action and a better pharmacokinetic profile than diazepam. Propofol, an intravenous anesthetic, has become very popular for gastrointestinal endoscopies in sedative doses. The opioid and benzodiazepine antagonists, naloxone and flumazenil, are indicated only in particular circumstances, like deep sedation with threatening respiratory depression. Ketamine and droperidol are not popular agents for sedation in the modern endoscopic practice.
\end{abstract}

Copyright $\odot 2010$ S. Karger AG, Basel
(C) 2010 S. Karger AG, Basel

$0012-2823 / 10 / 0822-0080 \$ 26.00 / 0$

Fax +4161306 1234

E-Mail karger@karger.ch

www.karger.com
Accessible online at: www.karger.com/dig

\section{Introduction}

To provide sedation effectively and safely, the physician must understand the pharmacology of the drugs. There is no single perfect drug for any particular patient.

Benzodiazepines and opioids are the commonest agents for sedation in gastrointestinal endoscopies, while propofol is becoming more and more popular [1-3]. Differences in pharmacokinetics (table 1) and pharmacodynamics render some of them advantageous over others. The doses mentioned in the text are by the intravenous route.

\section{Opioids}

Opiods exert their inhibitory actions directly via the opioid receptors ( $\mu, \kappa$ and $\delta$ ).

Meperidine has an analgesic potency $1 / 10$ th of morphine. One third of the dose is metabolized in the liver by $\mathrm{N}$-demethylation to norpethidine (convulsive agent), which is metabolized to norpethidinic acid and accumulated in renal failure. In cirrhosis and elderly patients, clearance is decreased. The drug is contraindicated in patients receiving MAOIs (tachycardia, hypertension, hyperpyrexia, convulsions). For endoscopic sedation, the initial dose is $25-50 \mathrm{mg}$ (additional doses: $25 \mathrm{mg}$ ), onset of action is 3-6 min and the duration of effect is $60-180$ $\min [4,5]$. 


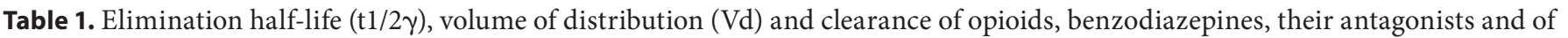
propofol

\begin{tabular}{|c|c|c|c|c|c|c|c|c|c|}
\hline & Meperidine & Fentanyl & Alfentanil & Remifentanil & Naloxone & Midazolam & Diazepam & Flumazenil & Propofol \\
\hline $\mathrm{t} 1 / 2 \gamma$ & $180-264 \mathrm{~min}$ & $219 \min$ & $100 \mathrm{~min}$ & $9-10 \mathrm{~min}$ & $64 \min$ & $2-4 \mathrm{~h}$ & $20-50 \mathrm{~h}$ & $0.7-1.3 \mathrm{~h}$ & $30-90 \mathrm{~min}$ \\
\hline $\mathrm{Vd}, \mathrm{l} / \mathrm{kg}$ & 3.8 & 4.0 & 0.86 & 0.35 & 1.8 & $1.1-1.7$ & $0.7-1.7$ & $0.6-1.6$ & $3.5-4.5$ \\
\hline Clearance, $\mathrm{ml} / \mathrm{min} / \mathrm{kg}$ & 15 & 13 & 6.4 & 40 & 30 & 7.5 & $0.2-0.5$ & $5-20$ & $30-60$ \\
\hline
\end{tabular}

Fentanyl is 600 times more lipid soluble and 100 times as potent as morphine. It is metabolized in the liver by dealkylation to norfentanyl (inactive). Fentanyl and norfentanyl are hydroxylated and excreted in the urine. In elderly patients and patients with liver disease, the $t 1 / 2 \gamma$ (elimination half-life) is increased. For endoscopic sedation, the initial dose is $50-100 \mu \mathrm{g}$ with additional doses of $25 \mu \mathrm{g}$ as required. The onset of action is 1-2 min and has a duration of 30-60 min [6].

Alfentanil's $t / 2 \gamma$ is increased in cirrhotic patients. In the liver, alfentanil undergoes $\mathrm{N}$-demethylation to noralfentanil. The same hepatic enzymes CYP3A3/4 are involved in alfentanil's and midazolam's metabolism, therefore coadministration of the two drugs prolongs their effect. The dose is $2.5-5 \mathrm{mg} / \mathrm{kg}$ and for continuous infusion $0.5-1.5 \mathrm{mg} / \mathrm{kg} / \mathrm{min}$ [7].

Remifentanil has a potency similar to the potency of fentanyl. It is rapidly hydrolyzed by nonspecific esterases in the blood and tissues to inactive metabolites. Its context-sensitive half-time is independent of the duration of infusion. The initial rate of the infusion is $0.1 \mu \mathrm{g} /$ $\mathrm{kg} / \mathrm{min}$ and subsequently titrated to $0.025-0.2 \mu \mathrm{g} / \mathrm{kg} /$ min. All opioids depress the central nervous, respiratory and cardiovascular system (particularly meperidine), and they increase the intrabiliary pressure, decrease gastric motility and cause nausea/vomiting and constipation. Though sufentanil, alfentanil and remifentanil are superior to fentanyl, fentanyl is a good choice with the less cost $[8,9]$.

Naloxone is a competitive antagonist at the $\mu, \kappa$, and $\delta$ receptors. It is metabolized in the liver to naloxone-3glucuronide. It reverses the effects of opioids (sedation, respiratory depression, delayed gastric emptying, pupillary constriction and analgesia). In patients dependent on opioids, it provokes acute withdrawal syndrome. It may cause hypertension, tachycardia, ventricular fibrillation, pulmonary edema, tachypnea, nausea, vomiting and seizures. The doses for depression and narcotic overdose are
$0.08-0.1$ and $0.4-1.0 \mathrm{mg}$ i.v. every $3 \mathrm{~min}$, respectively. The duration of the effect lasts 45-60 min. Respiratory depression and sedation may recur [10].

\section{Benzodiazepines}

The benzodiazepine receptor is part of the $\mathrm{GABA}_{\mathrm{A}^{-}}$ receptor complex on the subsynaptic membrane of the effector neuron. The receptor complex is made of the $\alpha$-, $\beta$ - and $\gamma$-subunits. The benzodiazepine binding site is located on the $\gamma$-subunit. With activation of the GABA $_{A}$ receptor, gating of the $\mathrm{Cl}^{-}$ion channel is triggered and the cell becomes hyperpolarized. Midazolam is metabolized in the liver by oxidation to $\alpha$-1-hydroxymidazolam, which has half the activity of midazolam and $t 1 / 2 \gamma 1 \mathrm{~h}$. Diazepam undergoes $\mathrm{N}$-demethylation to yield the active metabolite desmethyldiazepam, which via C-3-hydroxylation is metabolized to oxazepam. Benzodiazepines exert anxiolytic, sedative, hypnotic, amnesic, anticonvulsant and centrally produced muscle-relaxant properties, and decrease cerebral blood flow, cerebral metabolic rate, systolic and diastolic blood pressure, vascular resistance, tidal volume, and respiratory rate. The dose for midazolam is $1-2 \mathrm{mg}$ with additional doses of $1 \mathrm{mg}$ every $2 \mathrm{~min}$. The peak effect is obtained after 3-4 min and the duration of action is $15-80 \mathrm{~min}$. Diazepam is given in a dose of 5-10 $\mathrm{mg}$, has a peak effect $3-5 \mathrm{~min}$ and the duration of action $360 \mathrm{~min}$. The doses must be reduced in the elderly, morbidly obese and cirrhotic patients [11, 12].

Flumazenil is a competitive benzodiazepine receptor antagonist with some inverse agonist activity. It causes nausea, vomiting, headaches and dizziness. To reverse conscious sedation, the recommended bolus intravenous dose is $0.2 \mathrm{mg}$, repeated up to $1 \mathrm{mg}$. For overdose, a bolus intravenous dose of $0.2 \mathrm{mg}$ is given, followed by $0.3 \mathrm{mg}$, then $0.5 \mathrm{mg}$, up to a total dose of $3 \mathrm{mg}$. The continuous infusion dose is $0.5-1.0 \mu \mathrm{g} / \mathrm{kg} / \mathrm{min}$ [13]. 


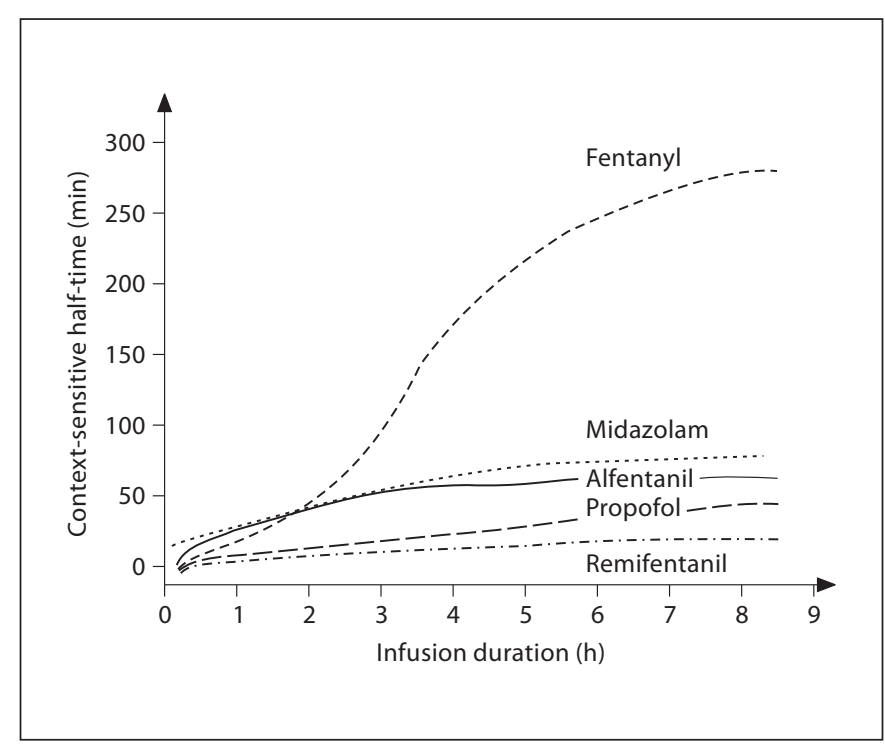

Fig. 1. Context-sensitive half-times of remifentanil, propofol, alfentanil, midazolam and fentanyl.

\section{Propofol}

The action of propofol is mediated via the $\beta 1$-subunit of the $\mathrm{GABA}_{\mathrm{A}}$ receptor. By activating the $\mathrm{GABA}_{\mathrm{A}}$ receptor, it increases the chloride conductance and results in hyperpolarization of the postsynaptic membrane. The drug undergoes hepatic and extrahepatic metabolism. It is 4-hydroxylated to 2,6-diisopropyl-1,4-quinol, which is excreted as glucuronide and sulfate conjugates. Propofol pharmacokinetics is independent of hepatic or renal function. Its context-sensitive half-time is much less dependent on the duration of the infusion compared to thiopental, while that of midazolam lies between the other two drugs (fig. 1). The $\mathrm{EC}_{50}$ of propofol to prevent movement is $16 \mu \mathrm{g} / \mathrm{ml}$ and $1.2 \mu \mathrm{g} / \mathrm{ml}$ for full orientation after recovery.

Propofol decreases cerebral blood flow, intracranial pressure and cerebral metabolic rate. In sedative doses, it increases the activity of beta waves in the EEG. Propofol decreases myocardial contractility and systemic vascular resistance, and causes hypotension. It causes bradycardia via a decrease in the calcium influx and sympathetic tone. During conscious sedation produced by propofol, the hypoxic respiratory drive is decreased by $80 \%$. This effect wears off $30 \mathrm{~min}$ after infusion discontinuation. Doses producing deep sedation decrease minute volume, increase end-tidal $\mathrm{CO}_{2}$, cause airway obstruction and relax the airway smooth muscle.
The recommended dose for endoscopic sedation is $10-40 \mathrm{mg}$ followed by incremental doses of $10-20 \mathrm{mg}$ or $25-75 \mu \mathrm{g} / \mathrm{kg} / \mathrm{min}$. The peak effect is obtained in $1-2 \mathrm{~min}$ and the duration of effect is $4-8 \mathrm{~min}$.

Fospropofol disodium is a water-soluble prodrug of propofol with a kinetic profile deprived of the high peak plasma concentrations occurring after administration of propofol [14-18].

\section{Ketamine}

Ketamine acts as noncompetitive antagonist of the NMDA receptors within the central nervous system, where it antagonizes the excitatory neurotransmitter glutamate. It also binds to opioid receptors. Ketamine increases the sympathetic outflow, thus increasing arterial blood pressure, heart rate, pulmonary artery pressure and cardiac output. It depresses respiration, laryngeal and airway reflexes to a lesser extent than other anesthetics, and it causes bronchodilatation, salivation, and postoperative nausea and vomiting. Auditory and visual hallucinations during emergence, restlessness, disorientation, and vivid dreams have been reported. Postoperatively, patients should be kept in a quite dark room without any stimulation. For endoscopic sedation, the initial intravenous dose is $0.5 \mathrm{mg} / \mathrm{kg}$, subsequently titrated to the desired effect. The duration of effect is $10-15 \min [19]$.

\section{Droperidol}

Droperidol produces central nervous system depression characterized by cataleptic immobility and marked apparent tranquility. It decreases the cerebral blood flow by $40 \%$. It may cause extrapyramidal effects, apprehension, excitation, restlessness and malignant neuroleptic syndrome. It has little effect on the respiratory system. It causes vasodilatation, decreases the arterial blood pressure, has no effect on cardiac contractility and prolongs the $\mathrm{QT}_{\mathrm{c}}$ segment. Droperidol is contraindicated in thyrotoxicosis, pheochromocytoma, Parkinson's disease and $\mathrm{QT}_{\mathrm{c}}$ prolongation. It is used as an antiemetic at doses $0.625-1.25 \mathrm{mg}$. For endoscopic sedation, the dose is $1.25-$ $2.5 \mathrm{mg}$ i.v. with an onset of action of 3-10 $\mathrm{min}$, and a duration of action of 3-6 h [20]. 


\section{References}

$>1$ Cohen LB, Hightower CD, Wood DA, Miller KM, Aisenberg J: Moderate level sedation during endoscopy: a prospective study using low-dose propofol, meperidine/fentanyl, and midazolam. Gastrointest Endosc 2004;59: 795-803.

$>2$ Vargo JJ: Propofol-mediated gastrointestinal endoscopy. Techniques in Gastrointestinal Endoscopy 2004;6:60-64.

3 Cohen LB, Delegge MH, Aisenberg J, Brill JV, Inadomi JM, Kochman ML, Piorkowski JD Jr: AGA Institute review of endoscopic sedation. Gastroenterology 2007;133:675-701.

4 Austin KL, Stapleton JV, Mather LE: Relationship between blood meperidine concentrations and analgesic response: a preliminary report. Anesthesiology 1980;53. 460-466.

$\checkmark 5$ Donnelly MB, Scott WA, Daly DS: Sedation for upper gastrointestinal endoscopy: a comparison of alfentanil-midazolam and meperidine-diazepam. Can J Anaesth 1994;41: 1161-1165.

6 Haberer JP, Schoeffler P, Couderc E, Duvaldestin P: Fentanyl pharmacokinetics in anaesthetized patients with cirrhosis. $\mathrm{Br}$ J Anaesth 1982;54:1267-1270.

7 Black E, Kay B, Healy TE: The analgesic effect of a low dose of alfentanil. Anaesthesia 1984;39:546-548.
8 Scott LJ, Perry CM: Remifentanil: a review of its use during the induction and maintenance of general anaesthesia. Drugs 2005; 65: 1793-1823.

>9 Kapila A, Glass PS, Jacobs JR, Muir KT, Hermann DJ, Shiraishi M, Howell S, Smith RL: Measured context-sensitive half-times of remifentanil and alfentanil. Anesthesiology 1995;83:968-975.

10 Ngai SH, Berkowitz BA, Yang JC, Hempstead J, Spector S: Pharmacokinetics of naloxone in rats and in man: basis for its potency and short duration of action. Anesthesiology 1976;44:398-401.

11 Horn E, Nesbit SA: Pharmacology and pharmacokinetics of sedatives and analgesics: Gastrointest Endosc Clin N Am 2004;14: 247-268.

12 Reves JG, Fragen RJ, Vinik HR, Greenblatt DJ: Midazolam: pharmacology and uses. Anesthesiology 1985;62:310-324.

13 Kulka PJ, Lauven PM: Benzodiazepine antagonists. An update of their role in the emergency care of overdose patients. Drug Saf 1992;7:381-386.
14 Sanna E, Garau F, Harris RA: Novel properties of homomeric beta 1 gamma-aminobutyric acid type A receptors: actions of the anesthetics propofol and pentobarbital. Mol Pharmacol 1995;47:213-217.

15 Hughes MA, Glass PS, Jacobs JR: Contextsensitive half-time in multicompartment pharmacokinetic models for intravenous anesthetic drugs. Anesthesiology 1992;76:334341.

16 Claeys MA, Gepts E, Camu F: Hemodynamic changes during anaesthesia induced and maintained with propofol. Br J Anaesth 1988;60:3-9.

17 Ebert TJ: Sympathetic and hemodynamic effects of moderate and deep sedation with propofol in humans. Anesthesiology 2005; 103:20-24.

18 Blouin RT, Seifert HA, Babenco HD, Conard PF, Gross JB: Propofol depresses the hypoxic ventilatory response during conscious sedation and isohypercapnia. Anesthesiology 1993;79:1177-1182.

19 White PF, Way WL, Trevor AJ: Ketamine its pharmacology and therapeutic uses. Anesthesiology 1982;56:119-136.

20 McKeage K, Simpson D, Wagstaff AJ: Intravenous droperidol: a review of its use in the management of postoperative nausea and vomiting. Drugs 2006;66:2123-2147. 